\title{
A participação do pai no parto domiciliar planejado: um ato significativo para a mulher
}

\author{
Father's participation in planned home birth: a meningful act for woman \\ La participación del padre en el parto en domicilio planeado: un acto significativo para la mujer
}

\author{
Jane Baptista Quitete'; Jéssika Andrade de Melo Braga Monteiro"
}

\begin{abstract}
RESUMO
Objetivo: discutir a participação do pai durante o trabalho de parto e parto sob a ótica da mulher. Método: pesquisa de natureza qualitativa, utilizando entrevistas semiestruturadas, com oito mulheres que tiveram parto domiciliar planejado e assistido por enfermeiras obstétricas no Estado do Rio de Janeiro. O projeto foi aprovado por Comitê de Ética em Pesquisa. Os depoimentos foram tratados por análise de conteúdo. Resultados: a análise dos dados evidenciou uma categoria temática denominada: significando a presença paterna, na qual se observa a importância do apoio paterno para a mulher, favorecendo o nascimento de forma mais natural e gerando sentimentos de segurança e amparo às mulheres. Conclusão: a participação do pai durante o trabalho de parto e parto foi considerada fundamental para as mulheres.

Descritores: Paternidade; parto domiciliar; parto humanizado; enfermagem obstétrica.
\end{abstract}

\section{ABSTRACT}

Objective: to discuss the father's participation in labour and childbirth from the women's perspective. Method: qualitative research, using semi-structured interviews with eight women who had a planned home birth attended by obstetric nurses in the State of Rio de Janeiro. The project was approved by Research Ethics Committee. The statements were analyzed using content analysis. Results: data analysis revealed a thematic category named: giving meaning to the father's presence, in which it is possible to understand the importance of father's support for women. Thus, natural birth becomes easier; women feel safer. Conclusion: the participation of the father during labor and childbirth was taken as fundamental for women.

Descriptors: Paternity, home birth, humanized delivery, obstetric nursing.

\section{RESUMEN}

Objetivo: discutir la participación del padre durante el trabajo de parto bajo la óptica de la mujer. Método: investigacíon de naturaleza cualitativa, utilizando entrevistas semi estructuradas, com ocho mujeres que tuvieron parto domiciliar planeado, asistido por enfermeras obstétricas em el Estado de Rio de Janeiro. El proyecto fue aprobado por Comité de Ética em Investigatición. Los datos fueron analizados utilizando análisis de contenido. Resultados: el análisis de los datos evidenció uma categoría temática denominada: significando la presencia paterna, en quese observa la importância del apoyo paterno para la mujer, favorecendo el nascimiento de forma más natural y generando sentimientos de seguridad y amparo a las mujeres. Conclusíon: la participacíon del padre durante el trabajo de parto fue considerada fundamental para las mujeres.

Descriptores: Paternidad; parto domiciliar; parto humanizado; enfermería obstétrica.

\section{INTRODUÇÃO}

O parto domiciliar planejado veio para resgatar o parto na sua forma mais natural, partindo do pressuposto que o parto é um processo fisiológico, assim como veio também resgatar a autonomia da mulher que foi cerceada com a institucionalização do parto. No parto domiciliar, a mulher pode dar a luz em um lugar que ela se sinta segura, que no caso da gestante de risco habitual pode ser seu próprio domicilio ${ }^{1,2}$.

Com a institucionalização do parto na década de 1940, a mulher deixou de ser acompanhada por familiares em sua casa durante o trabalho de parto e parto, e passou a estar sozinha nesse evento, visto que a instituição hospitalar não foi planejada para ter um acompanhante nesse processo ${ }^{2,3}$.

O parto domiciliar planejado foi resgatado na década de 1990, como movimento de luta das mulheres contra a medicalização do parto, com apoio da Organização Mundial da Saúde (OMS) e de setores organizados da sociedade, que culminaram em políticas públicas que favoreceram a atuação de enfermeiras obstétricas na assistência aos partos domiciliares planejados, nos centros urbanos ${ }^{1}$. As enfermeiras obstétricas consideram o parto como evento natural, feminino, fisiológico e íntimo ${ }^{4}$. O objetivo das enfermeiras obstétricas no parto 
domiciliar é justamente resgatar o parto na sua forma mais natural, pois o ambiente do domicílio favorece a evolução fisiológica do parto para que as mulheres possam vivenciar esse momento de modo prazeroso ${ }^{1}$.

A presença do pai como acompanhante do parto é objeto de vários estudos, revelando sua importância, vantagens e benefícios, mas, na prática obstétrica, o homem é visto com preconceito ${ }^{3}$. Mesmo com a Lei do Acompanhante (Lei 11.108/ 2005), que garante às parturientes o direito à escolha de um acompanhante durante todo trabalho de parto, parto e pós-parto imediato, no âmbito do Sistema Único de Saúde ${ }^{5}$, muitos profissionais ainda não percebem a importância da presença do pai, para a mulher e para o bebê .

Esta pesquisa teve o objetivo de discutir a participação do pai durante o trabalho de parto e parto sob a ótica da mulher, isto é, compreender como as mulheres se sentem em ter o pai como participantes do processo de nascimento no domicílio. Tendo como objeto a participação do pai no parto domiciliar planejado, buscando, assim, retratar como é para a mulher ter o pai como acompanhante no trabalho de parto e parto.

\section{REVISÃo DE LITERATURA}

A assistência no momento do nascimento ainda é muito centralizada na mulher e no bebê, colocando em segundo plano o homem. A participação do pai traz um misto de sentimentos não só para o homem, mas principalmente na mulher que se sente mais segura e preparada para esse momento especial, além de estimular a criação de vínculo marido/esposa, pai/filho. A participação do pai oferecendo apoio emocional, ajudando a mulher a suportar melhor a dor e a tensão do parto, a presença de alguém de sua confiança ao seu lado faz com estas se sintam mais satisfeitas, confiantes e felizes ${ }^{3}$.

A reinserção do pai na sala de parto acontece em 1970, com o objetivo de recuperar a efetividade, valorização da mulher e referências familiares, valores estes perdidos na passagem do parto domiciliar para o parto hospitalar ${ }^{3,4}$.

Com a medicalização do parto houve uma exclusão de não médicos no acompanhamento do trabalho de parto, o que deixou uma lacuna. Há uma relação desigual entre os profissionais e os acompanhantes, dado a um modelo hierarquizado de assistência à saúde. Os acompanhantes são vistos com certo preconceito pelos profissionais de saúde, que alegam falta de estrutura física que comporte o acompanhante (ambiente, roupa cirúrgica, superlotação nas maternidades) e falta de preparo do acompanhante para assistir ao parto 3 . Por estes motivos, nem sempre o desejo do homem de compartilhar o nascimento do seu filho é concretizado.

A participação do homem nas maternidades é um evento relativamente recente, que iniciou na década de
1980, nas maternidades privadas. Nas maternidades públicas, a participação do pai no trabalho de parto começou a ser permitida e encorajada, a partir da década de 1990, sobretudo, naquelas que buscam atender de acordo com a filosofia do parto humanizado ${ }^{6}$.

\section{METOdOLOGIA}

Trata-se de uma pesquisa descritiva com abordagem qualitativa e de campo, considerando a subjetividade do objeto de pesquisa - a participação do pai no parto domiciliar planejado, sob a ótica das mulheres.

O procedimento para coleta de dados ocorreu por meio da técnica de bola de neve ou snowball método de amostragem intencional que permite a definição de uma amostra por meio das indicações procedidas por pessoas que compartilham ou conhecem outras com características em comum de interesse do estudo ${ }^{7}$. O ponto de partida para a seleção das participantes ocorreu através de enfermeiras obstétricas que indicaram mulheres que haviam sido acompanhadas por elas no Estado do Rio de Janeiro. As primeiras entrevistadas indicaram outras e assim, sucessivamente, até que ocorresse a repetição dos dados. A coleta de dados foi encerrada após a oitava entrevista.

Os critérios de inclusão foram: ter tido pelo menos um dos seus filhos por parto natural em casa, denominado parto domiciliar planejado, o parto ter sido assistido por enfermeiras obstétricas no Estado do Rio de Janeiro, aceitar voluntariamente participar da pesquisa, ter tido o pai como acompanhante do trabalho de parto e parto, ter mais de 18 anos de idade.

Para a coleta de dados foi realizada uma entrevista semiestruturada, que abordou questões sobre a gestação e parto, tendo como pergunta norteadora do estudo: O pai participou do processo de nascimento? Se sim, como você se sentiu tendo o pai ao seu lado durante todo esse processo?

As entrevistas foram gravadas por equipamento digital media player, ouvidas e transcritas pela pesquisadora. Os dados oriundos da transcrição dos depoimentos passaram por leitura exaustiva, fracionamento dos incidentes, nomeação dos incidentes, agrupamento temático e nomeação de categorias temáticas, conforme recomenda o referencial metodológico de Bardin ${ }^{8}$.

Foi mantido o anonimato das oito entrevistadas, (E), cujos depoimentos forma identificados por E1, E2, E3...

Esta pesquisa é um recorte da tese de doutorado, intitulada Atribuindo significados 'as enfermeiras obstétricas: uma construção social sob a ótica das usuárias na perspectiva do interacionismo simbólico ${ }^{9}$, e atendeu a todas as recomendações da Resolução no 466/2012 do Conselho Nacional de Saúde. O projeto foi aprovado pelo Comitê de Ética em Pesquisa da Universidade do Estado do Rio de Janeiro. 


\section{RESULTADOS E DISCUSSÃO}

A análise dos dados revelou uma categoria temática, que respondeu ao objeto desta pesquisa, intitulada: Significando a presença paterna.

Os sentimentos das mulheres quanto à participação dos pais no parto são positivos. Elas relatam que eles ajudaram no decorrer do trabalho de parto, pois se sentiram amparadas e seguras com a presença do pai durante o trabalho de parto e parto. A presença do acompanhante traz conforto, segurança e confiança ${ }^{6}$, e configura-se como apoio emocional ${ }^{2,10}$.

Foi muito legal. Foi muito bacana. Eu me senti amparada.(E2)

Mas eu senti que eu estava segura, que eu podia me entregar, eu me senti segura de poder viver intensamente esse processo.(E5)

Então, você já sente aquilo como uma força muito grande também.(E1)

A parturiente necessita de apoio contínuo durante o parto e, quando esse apoio é dado por membro da família, as mulheres têm uma avaliação do parto mais positiva, sentem-se mais satisfeitas e felizes ${ }^{10}$. A participação do pai no parto é percebida pelas mulheres como algo muito importante, fundamental e essencial para que o processo de nascimento de seus filhos acontecesse de forma natural. Este fato é ratificado por estudos que asseguram ser a presença de um acompanhante durante o trabalho de parto um fator que promove a saúde física e psíquica da parturiente ${ }^{6}$.

Ao vivenciar o processo de nascimento, o homem, desfruta de um momento intenso, repletos de significativos, sentimentos e reflexões ${ }^{3}$, favorecendo a corresponsabilização do homem e da mulher no processo parturitivo e no nascimento do filho, que por sua vez fará nascer um novo homem, um novo pai ${ }^{11}$, permitindo, assim, o delineamento de um novo papel que o mesmo irá exercer².

É muito importante a participação do pai. [...] ajuda muito mesmo, é muito importante. (E3)

Pra mim, foi fundamental o papel do dele [pai]. A presença dele na hora do parto para mim era fundamental para eu manter meu equilibrio. (E2)

O pai, eu acho que é essencial. A presença dele ali foi essencial para mim. (E8)

Fundamental [a participação do pai], essa é a palavra. (E6)

As mulheres sabiam que os pais estariam com elas para o que precisassem. Elas sabiam que podiam contar com a presença deles, que podiam se entregar ao trabalho de parto, pois o pai estaria ali para dar todo o suporte necessário.

Não precisava me preocupar com nada porque ele [pai] estava ali para me assessorar. Eu via que ele estava ali, assim pelos lados. (E5)
A presença do acompanhante na sala de parto é considerada um método não farmacológico para a redução da dor ${ }^{12}$. Estudos apontam, ainda, que a presença do pai contribui para a diminuição das experiências dolorosas e do sofrimento, por vezes vivenciados por mulheres no cenário do nascimento, além de evitar procedimentos desnecessários (manobra de kristeller, toque vaginal repetidos, episiotomia, ocitocina, dentre outros), diminuindo assim as intercorrências durante o processo de nascimento ${ }^{6,13,14}$. A presença do acompanhante também é considerada uma estratégia para a humanização do parto e do nascimento, pois faz valer os direitos da mulher que se encontra vulnerável durante o trabalho de parto e parto ${ }^{14}$.

Eu até me surpreendi com ele [pai] ali, na hora do parto. Ele me surpreendeu. (E4)

Segundo as mulheres, os pais pariram junto com elas. O trabalho de parto e parto, conforme as depoentes, foi vivenciado pelo casal, foi um trabalho em conjunto, intimo e familiar. Os partos assistidos no domicílio propiciam uma maior participação paterna, além de promover maior domínio e controle da situação pelo casal, sensação de liberdade e responsabilidade, motivos que levam casais a optarem pelo parto assistido em casa ${ }^{15}$.Além disso, as profissionais atuantes no parto domiciliar (enfermeiras obstétricas) percebem o pai/acompanhante, não como um estranho naquele ambiente, e sim como alguém capaz de favorecer positivamente a fisiologia do parto, com foco em um cuidar humanizado e pautado no respeito aos envolvidos ${ }^{2}$.

Os pais têm tido uma participação cada vez mais ativa durante o pré-natal, o trabalho de parto e o parto, se permitem ficar emocionados por serem os primeiros a pegar os filhos no colo ou por cortarem o cordão umbilical ${ }^{3,15}$.A principal motivação do pai em participar do parto ainda é o fato de proteger sua companheira e apoia-la, promovendo bem-estar físico e psicológico, assim como favorecendo o vínculo precoce com seu filho ${ }^{3}$.

Na verdade eu costumo dizer que ele [pai] pariu junto comigo, que não foi um parto só meu. Ele pariu, nas duas vezes. Sentiu a dor, eu acho, comigo, nessas duas vezes. (E8)

Ele [pai] fala que pariu junto comigo, e ele pariu mesmo. (E2)

Eu não senti que foi um trabalho meu. Eu senti que foi um trabalho em conjunto, que foi um trabalho de parto dos dois. (E5)

Visto os benefícios da presença do companheiro, os profissionais de saúde deveriam acolhê-los e incentivá-los desde o pré-natal até o parto, estendendo-se ao puerpério e aleitamento materno, minimizando assim os medos e anseios com o nascimento ${ }^{16}$, e entendendo que a participação ativa do pai em todo este processo deve ter início o mais precoce possível².

Para o homem ocorre afirmação de sua paternidade quando vivencia o nascimento de seus filhos, 
valorizando seu papel de pai, constituindo-se também em uma possibilidade de amadurecimento pessoal, pois proporciona uma reflexão sobre o valor da vida e a relação conjugal, trazendo repercussões positivas para o casal e para a sociedade ${ }^{3,15,17}$.

Os homens que participam ativamente da experiência do parto passam a ter mais respeito pelas mulheres. Tornam-se homens mais participantes no cuidado com os filhos, no planejamento de uma futura gravidez e na subsistência da família ${ }^{15}$. A imagem do homem dominador e insensível poderá dá lugar a um novo ser capaz de se envolver emocionalmente ${ }^{15}$.

\section{CONCLUSÃO}

O objetivo deste estudo foi alcançado, pois foi constatada a importância da participação do pai no trabalho de parto e parto sob a ótica das mulheres.

A participação do pai, além de favorecer o desenvolvimento do trabalho de parto e diminuir as intervenções obstétricas, reforça sentimentos como segurança, força, amparo para as mulheres. Sentimentos que, durante o trabalho de parto e do parto, ajudam a mulher a se entregar, favorecendo seu desempenho.

Ainda hoje, pouco se vê ou se fala sobre a presença e participação do pai no momento do parto, visto que a gestação e o parto ainda são considerados eventos femininos, onde, consequentemente, o pai tem sido excluído. Em oposição a esta realidade, no parto domiciliar planejado, e a participação do pai é ativa. O pai é visto como elemento coparticipante junto com a mulher.

Destacam-se, como limitações deste estudo, as reduzidas produções científicas sobre o tema e amostra, a qual não representa o universo do fenômeno investigado, impedindo, assim, a generalização dos achados. Entretanto, os resultados desta pesquisa refletem uma realidade local, e pode subsidiar novas pesquisas.

\section{REFERÊNCIAS}

1. Lessa HF, Tyrrell MAR, Alves VH, Rodrigues DP. informação para a opção pelo parto domiciliar planejado: um direito de escolha das mulheres. Texto \& contexto enferm. [Online]. 2014 July [citado em 18 jan 2018]; 23(3):665-72. Disponível em: http://www.scielo.br/ pdf/tce/v23n3/pt_0104-0707-tce-23-03-00665.pdf.

2. Carvalho IS, Carvalho CFS, Enders BC, Brito RS. A participação do homem durante o nascimento do filho: vídeos do Youtube. Rev. enferm. UERJ. 2017 [citado em jan 2018]; 25(e11474):1-6. Disponível em: DOI: http://dx.doi.org/10.12957/reuerj.2017.11474. 3. Jardim DMB,Penna CMM. Pai-acompanhante e sua compreensão sobre o processo de nascimento do filho. REME rev. min. enferm. [Internet]. 2012 [citado em 20 mar 2017]; 16(3):373-81. Disponível em:DOI: http://www.dx.doi.org/S141527622012000300009.
4. Koettker JG. O parto domiciliar planejado assistido por enfermeiras [dissertação de pós-graduação]. Florianópolis(SC): Universidade Federal de Santa Catarina; 2010. [citado em 18 jan 2018 ]. Disponível em : http://repositorio.ufsc.br/hanvghdle/123456789/93958.

5. Ministério da Saúde (Br). Lei no 11.108, de 07 de abril de 2005. Altera a Lei no 8.080, de 19 de setembro de 1990, para garantir às parturientes o direito à presença de acompanhante durante o trabalho de parto, parto e pós-parto imediato, no âmbito do Sistema Único de Saúde.Brasília (DF):Senado Federal; 2005.

6. Motta CCL, Crepaldi MA. O pai no parto e o apoio emocional: a perspectiva da parturiente. Paidéia. [Online]. 2005 [citado em 18 jan 2018]; 15(30):105-18. Disponível em: $D O I=10.1590 /$ S0103863X2005000100012\&pi=S0103$-863 \times 2005000100012 \&$ pdf_path=paideia/v15n30/12. pdf\&lang=pt.

7. Goodman LA. Snowball sampling. Ann. Math. Statist. [Online] 1961 [cited 2018 Jan 18]; 32(1): 148-70. Available from: DOI: 10.1214/aoms/1177705148. https://projecteuclid.org/euclid. aoms/1177705148.

8. Bardin L. Análise de conteúdo. São Paulo: Edições 70; 2011.

9. Quitete JB. Atribuindo significados às enfermeiras obstétricas: uma construção social sob a ótica das usuárias na perspectiva do interacionismo simbólico [tese de doutorado]. Rio de Janeiro: Universidade Estadual do Rio de Janeiro; 2015.

10.Dodou HD, Rodrigues DP, Guerreiro EM, Guedes MVC, Lago PN, Mesquita NS. La contribucióndelacompañante para lahumanizacióndel parto y nacimiento: percepciones de mujeresdespuésdel parto.Esc. Anna Nery Rev. Enferm. [Online] 2014 [citado em 10 ene 2018]; 18(2):262-9. Disponible en: http://dx.doi. org/10.5935/1414-8145.20140038.

11. Melo RM, Brito RS. The perception of men/companions with regard to their presence at the birth of a child. Rev. enferm. UFPE on line. 2011 [cited 2018 June 10]; 5(10):2585-9. Available from: http://www.revista.ufpe.br/revistaenfermagem/index.php/revista/article/view/2085/pdf_741.

12. Oliveira ASS, Rodrigues DP, Guedes MVC, Felipe GF, Galiza FT, Monteiro LC. O acompanhante no momento do trabalho de parto e parto: percepções de puérperas. Cogitare enferm. Rev. [Online] 2011 [citado em 12 jan 2018]; 16 (2): 247-53. Disponível em: https://revistas.ufpr.br/cogitare/article/viewFile/20201/14211.

13. Perdomini FRI, Bonilha ALL. A participação do pai como acompanhante da mulher no parto. Texto \& contexto enferm. 2011 [citado em 12 jan 2018]; 20(3):445-52. Disponível em: http:// www.scielo.br/pdf/tce/v20n3/04.pdf.

14. Vargens OMC, Nunes S, Silva CM, Progianti JM. Procedimentos invasivos no cuidado à parturiente sob a perspectiva de gênero. Rev. enferm. UERJ. 2016 [citado em 12 jan 2018]; 24(6):e15066. Disponível em: DOI: http://dx.doi.org/10.12957/ reuerj.2016.15066.

15. Cardoso BM da C. O papel do pai no trabalho de parto [dissertação de mestrado]. Porto(Pt): Escola Superior de Enfermagem do Porto; 2017.

16. Matos MG, Magalhães AS, Carneiro TF, Machado RN. Construindo o vínculo pai-bebê: a experiência dos pais. Psico-USF. [Online] 2017 [citado em 10 jan 2018]; 22(.2):.261-71. Disponível em: http://dx.doi.org/10.1590/1413-82712017220206.

17. Antunes JT, Pereira LB, Vieira MA, Lima CA. Presença paterna na sala de parto: expectativas, sentimentos e significados durante o nascimento. Rev. enferm. UFSM. 2014 [citado em 14 jan 2018]; 4(3):536-45. Disponível em: http://dx.doi. org/10.5902/2179769212515. 